\title{
NOTAS
}

\section{EL CODO ARDIENTE: TESTIMONIOS DE UN EUFEMISMO ERÓTICO DE LOS SIGLOS DE ORO}

Uno de los poemas más agudos y picantes de los que alumbró el desenfadado ingenio de don Jerónimo de Barrionuevo ( ca. 1587-ca. 1671), canónigo de Sigüenza y uno de los más destacados autores de prosa noticiera y de poesía erótica de su tiempo, es el que dice:

El codico me arde, madre; madre mía, el codo me arde.

El pie en una estaca topando aier tarde, me di un tropezón que al suelo acabase; en mitad del codo fue el golpe tan grande que llegó la vista a despabilarse; como una estocada pudiera pasarme, a no estar las sayas hasta los ijares. Madre mía, el codo me arde.

Búsqueme, señora, emplastos y naves, y hálleme un médico para que me sane; ponga cosas tiesas con que se me ablande, que yo no hago caso de las flojedades; sáqueme el bustillo dentre aquesos naipes, que puede sin duda él solo sanarme.
Madre mía, el codo me arde.

No diga al vecino que acá se nos pase, porque no entretenga con dos disparates; mire que es un hombre que de todo sabe, algibrista bravo, médico del arte, que tiene la mano tan hecha a desastres que quita dolores solo en un instante. Madre mía, el codo me arde.

Si desto no gusta, tráigase acá un fraile, mire que deseo mucho confesarme, que de su cordón milagros bastantes se han visto en mujeres llegando a tocarle; podrá ser que pueda esto mitigarse, si no es que el hisopo del cura lo aplaque. Madre mía, el codo me arde ${ }^{1}$.

${ }^{1}$ El poema se ha conservado en el manuscrito 3736 de la Biblioteca Nacional de Madrid, pp. 263-264. Sobre este poema, véase mi artículo "Flor de canciones tradicionales inéditas de los Siglos de Oro: el cancionero de Jerónimo de Barrionuevo 
La cabeza del villancico que de forma tan desenfadada glosó Barrionuevo ("El codico me arde madre /madre mía el codo me arde") tiene todo el aspecto, pese a que no se conocen más testimonios que corroboren su difusión en aquella época, de haber sido tradicional en el Siglo de Oro, como buena parte de los otros villancicos que glosó el canónigo de Sigüenza. En cualquier caso, sí que es indicio de tradicionalidad el que esté basado en un eufemismo de tipo sexual, el de la equivalencia $\operatorname{codo}=$ coño, que sabemos a ciencia cierta ha tenido algún arraigo en el habla coloquial y en la cultura oral de los siglos XVI y XVII especialmente, con algún eco que ha llegado incluso hasta el xx.

Efectivamente, ya Pere Vallés, en su Libro de refranes publicado en 1549, incluía el refrán "dolor d'codo: dolor d'esposso: duele mucho: y dura poco" 2 , cuyo sentido, al ser explicado dos décadas después, en 1568, por Ioan de Mal Lara en La Philosophia Vulgar, quedaba mucho mejor aclarado:

Dolor de esposo, dolor de cobdo, duele mucho y dura poco: Puede se entender esto en dos maneras. La vna que al principio del amor en el esposo, es gran dolor si se absenta, ò va lexos tierra, ò se muere. Pero como era alos principios y el amor no auía tomado fundamento, ni auía prendas entre ellos que les doliessen, solamente se sintió dolor grandemente por la falta delo venidero. Pero las viejas dan otro y creo que es más verdadero, porque lo he oýdo algunas vezes que el amor del esposo, entra dando dolor quandose casa con donzella, y porque la esposa, no auiendo vsado tal cosa siente dolor al principio, consuelan la con dezir que aunque duele mucho, dura poco, de manera que es semejante al dolor del cobdo, que por estar en huesso, es grande, pero dura poco, y también deue el refrán de jugar del vocablo cobdo. \&c. ${ }^{3}$

"Y también deue el refrán de jugar del vocablo cobdo. \&c.". Con este eufemístico circunloquio aludía Mal Lara al tercer sentido "del vocablo cobdo" en este contexto: el erótico-humorístico, que debía ser, pese al recatado tercer lugar en que él lo arrinconó, el más próximo y el que mejor reconocerían el común de sus contemporáneos.

Es lástima que, cuando Gonzalo Correas, en su Vocabulario de refranes de 1627, ofreció este mismo refrán, "Dolor de esposo, dolor de

(B.N.M. Mss. 3736) y otros manuscritos madrileños”, RFilR, 11/12 (1994-95), 309325. Aunque este manuscrito lleva en portada el título de Comedias y poesías varias por Don Juan Cantón de Salazar, y la fecha de 1700, lo cierto es que hay acuerdo general entre los críticos en la atribución a "D. Hierónymo Barrionuevo y Peralta, Canónigo de Sigüenza”, y en la datación en torno a 1641-1643. Sobre Barrionuevo, puede verse además el trabajo de José Ramón Fernández de Cano y Martín, "Don Jerónimo de Barrionuevo, poeta castrado", Estado actual de los estudios sobre el Siglo de Oro: Actas del II Congreso Internacional de Hispanistas del Siglo de Oro, eds. M. García Martín, I. Arellano, J. Blasco y M. Vitse, Universidad, Salamanca, 1993, t. 1, pp. 347-355.

2 Zaragoza, en Casa de Juana Milian..., f. 23r.

${ }^{3}$ Hernando Díaz, Sevilla, f. 72v. 
kodo: duele mucho i dura poko"4, no le añadiese uno de los agudos comentarios a los que tan aficionado era. Afortunadamente, esta ausencia se vio compensada por la explicación de don Luis Galindo en sus Sentencias filosóficas y morales de hacia 1660-1669: "Dolor de cobdo dolor de esposo; duele mucho y dura poco... comparando este dolorzillo agudo al que la donzella padeze en la entrada primera dela consumación de su matrimonio. Y por honestidad vsa este Castellano del equíuoco" . De nuevo el reconocimiento del valor eufemístico de la expresión ("equíuoco por honestidad") reafirma el evidente simbolismo sexual que este cobdo debía de tener en época de Galindo.

Más codos de este tipo aparecen en otros textos literarios de la época. De nuevo en el inagotable Vocabulario (1627) de Correas encontramos un ejemplo adicional y revelador de la metáfora erótica que estamos analizando: "A tu marido, muéstrale el kodo, mas no del todo". En el mismo lugar anotó Correas otras variantes, todas ellas dotadas de un doble sentido inconfundible: "a tu espó, muéstrale el kó, mas no del tó", "a tu esposo, muéstrale, mas no del todo"; "a tu marido, muéstrale lo otro, mas no del todo". El comentario acompañante aconsejaba el mismo recato en los gestos de la mujer que el refrán mostraba en el lenguaje: "akonséxala ke no dé indizio de desonesta, i ke sea sekreta; i a todos, ke sean advertidos i la traten kon rrekato i rresguardo"6.

Los cancioneros y romanceros de finales del siglo xvi y comienzos del xvII fueron muy fecundos en la documentación del vocablo codo con doble sentido erótico. En un romancillo erótico publicado por primera vez en la Séptima parte de Flor de varios romances (1595), de donde pasaría después al Romancero general de 1600-1605, la alusión a un

${ }^{4}$ Vocabulario de refranes y frases proverbiales, ed. L. Combet, Université, Bordeaux, 1967, p. 333.

5 Sentencias filosóficas $i$ verdades morales, que otros llaman prouerbios o adagios castellanos, 10 ts. [B.N.M. Mss. 9772-9781], t. 5: [Ms. 9776], ff. 9v-10r.

${ }^{6} \mathrm{G}$. Correas, Vocabulario de refranes, p. 24. Un siglo antes que Correas, Francisco Delicado había incluido el mismo refrán en El retrato de la Lozana andaluza (cf. la ed. de C. Allaigre, Cátedra, Madrid, 1985, mamotreto 3, p. 180): "amuestra a tu marido el copo, mas no del todo", utilizando la metáfora del copo, que también equivalió en su época a coño. Lo prueba, por ejemplo, la célebre composición del Cancionero musical de Palacio: "Una moçuela de Logroño / mostrado me avía su co... / po de lana negro que hilava". O el poema dieciochesco de Samaniego: "La monja, como era lega / y profesaba al otoño, / rabiaba por darle entrada / y le enseñaba su co... / su copo con que ella hilaba”. La canción fue editada en La música en la corte de los Reyes Católicos, t. 4-2: Cancionero musical de Palacio. (Siglos $x v$-xvi), vol. 3-B, ed. J. Romeu Figueras, CSIC, Barcelona, 1965, núm. 141, y reproducida en MARGit Frenk, Corpus de la antigua lírica popular hispánica. (Siglos xv a xvii), Castalia, Madrid, 1987, núm. 1719. El poema de Samaniego fue editado en El jardín de Venus, ed. E. Palacios, A-Z Ediciones, Madrid, 1991, p. 172. Sobre ambos poemas, y sobre el recurso poético que los informa, véase mi artículo "Mozas de Logroño y defraudación obscena en el cancionero popular: del Cancionero musical de Palacio al folklore moderno", Revista de Folklore, 1993, núm. 153, 75-82. 
codo localizado sorprendentemente "por las piernas" de "las vecinas" no dejaba demasiadas dudas sobre su verdadero sentido:

\author{
Madrugastes vezina mía \\ a sacar pollos, \\ plega a Dios no os encue[n] tre el duende \\ y os coma el coco. \\ Dizen las vecinas, \\ que ceuan palomas, \\ y las que del huerto \\ coxen los cogombros, \\ que a penas se acuestan, \\ y cierran los ojos, \\ cuando, con vn huesso, \\ de la mano al codo, \\ las dan por las piernas \\ golpes tan sabrosos \\ que cruxen los dientes \\ de dentera todos... ${ }^{7}$
}

Un villancico glosado que aparece en el Cancionero musical de Módena, compilado justo por aquellos años, proclamaba:

A my gusto me acomodo

Madre mía en buena fe, que si se me rompe el codo codi $[\mathrm{r}]$ rota me quedaré.

7 Séptima parte de Flor de varios romances nueuos recopilados de muchos autores por Francisco Enríquez, Casa de la bivda de Alonso Gómez, Madrid, 1595, ff. 137v-138r. Hay reedición facsímil de Antonio Rodríguez Moñino en el noveno de los doce tomos de sus Fuentes del Romancero General (Madrid, 1600), Real Academia Española, Madrid, 1957. La composición puede verse también en la moderna edición del Romancero General (1600, 1604 y 1605) de Ángel González Palencia, CSIC, Madrid, 1947, núm. 613. También la editaron Pierre Alzieu, Robert Jammes e Yvan Lissorgues en su Poesía erótica del Siglo de Oro, Crítica, Barcelona, 1983, núm. 49. Los editores franceses explicaron la expresión de la mano al codo como equivalente a "un codo de largo. Pero es difícil precisar más, ya que hubo varias medidas de longitud llamadas codo. «Las medidas del codo fueron diversas - dice Covarrubias-; una del codo a la mano, otra que llamavan codo real, y el tercero codo geométrico». Hubo más. Para abreviar, diremos que el codo puede tener entre 44 y 72 centímetros. ¡Lo que puede el miedo en la imaginación de una mujer!". A este comentario se puede ahora añadir que aunque, efectivamente, el poema juega con la expresión de la mano al codo en su acepción de 'medida de longitud', la exploración del sentido metafórico de la voz codo que estamos realizando avala que opera también, intencionadamente, con el equívoco codo/ coño. Máxime cuando pone en escena un codo que no tiene relación con los brazos, sino con las piernas de las mujeres: “...cuando, con un hueso / de la mano al codo, / las dan por las piernas / golpes tan sabrosos...”. 


\section{Coplas}

Madre, de qué se alborota que más uale por su uida ser rica y codi $[\mathrm{r}]$ rompida que no pobre y codi[r] rota. Que si no es deste modo no se puede andar a fe que si se me rompe el codo codi[r]rota me quedaré.

Y aunque a su gusto no quadre Madre mía no se aflija. Basta lo que he sido hija déxame agora ser madre que si a madre me acomodo qué de nietos que le haré que si se me rompe el codo codi[r]rota me quedaré.

No quiero calamitades ni estar suspensa contino. Mejor es abrir camino a tantas dificultades. Y abierto a Roma por todo como las demás iré que si se me rompe el codo codi [r] rota me quedaré ${ }^{8}$.

La misma cancioncilla aparecería así, con la indicación de que era "cantar i rrefrán", en el Arte de la lengua de Gonzalo de Correas: "Que si à todo le doi de codo, madre mía, en buena fe, que si à todo le doi de codo, codirrota me quedaré"9.

Una seguidilla vieja de los inicios del siglo XVII aludía de este modo a las enfermedades venéreas de las prostitutas:

-Putas, Puticas, Putacas, ¿qué traeis en aquesos codos?

-Bubas, encordios, demonios, pujabantes i tenaças ${ }^{10}$.

8 Charles V. Aubrun, "Chansonniers musicaux espagnols du xviI e siècle. II. Les recueils de Modène”, BHi, 52 (1950), 313-374. Cf. M. FrENK, Corpus, núm. 1551.

${ }^{9}$ Arte de la lengua española castellana, ed. E. Alarcos García, Revista de Filología Española, Madrid, 1954, p. 328.

${ }^{10}$ La seguidilla fue anotada en el Manuscrito 3915 [Parnaso Español] de la B. N. M., f. 319v; fue reproducida en R. Foulché-Delbosc, "Séguedilles anciennes", $R H i$, 8 (1901), 309-331, núm. 330. 
Y un romance artificioso y anónimo del mismo siglo decía:

Muy enferma está Marica,
la hija de Andrés Chamorro,
de un gran dolor que le traba
vientre, cadera y lomos.
Dicen que su mal procede
de la picada de un bromo,
porque, lavando en la mar,
quiso meterse a lo hondo.
Otros dicen que, tendiendo
los palos en un madroño,
cayó y metióse, al alzar,
un garrancho por el codo...

La abundancia de documentación del vocablo codo con doble sentido sexual en los siglos XVI y xvII revela que este uso debió ser corriente en aquellos tiempos. El hecho de que su rastro parezca perderse casi del todo después de aquella época puede ser debido a que esa acepción decayera efectivamente en el habla coloquial, o a que los escritores del siglo xviII en adelante no supieron reflejar con la misma viveza que los de siglos anteriores el registro más vulgar de la lengua, al que sin duda perteneció este ingenioso eufemismo. Es difícil pronunciarse al respecto. Algunos de los más importantes diccionarios o repertorios de eufemismos de hoy en día (incluyendo los de Camilo José Cela) silencian completamente esta acepción. Pero que no está definitivamente muerta lo prueba el que, tras un prolongado silencio documental de varios siglos, todavía sigan asomando estos equívocos codos entre los versos de una canción carnavalesca que es posible escuchar todavía hoy en el pueblo de Priego (Córdoba):

$$
\begin{aligned}
& \text { Una niña muy bonita } \\
& \text { que a su balcón se asomaba } \\
& \text { y un caballero al pasar } \\
& \text { con atención la miraba. } \\
& \text { Y la niña le decía: } \\
& \text { "Cara de carnero mocho". } \\
& \text {-Dispense usted, señorita, } \\
& \text { que le estaba viendo... el codo }{ }^{12} \text {. }
\end{aligned}
$$

11 Antologado en JoaQuín López Barbadillo, Cancionero de amor y de risa en que van juntas las más alegres, libres y curiosas poesías eróticas del Parnaso español, muchas jamás impresas hasta ahora y las restantes publicadas en rarísimos libros, Akal, Madrid, 1977, pp. 93-94.

12 Enrigue Alcalá Ortiz, Cancionero popular de Priego: poesía cordobesa de cante y baile II, Priego, [edición del autor], 1986, p. 180, núm. 1498. El verso que dice "cara de carnero mocho" es en realidad una fórmula perteneciente a un cuento muy difundido en España y en Portugal que he estudiado en mi artículo "Correspondencias folclóricas españolas de la Farsa de Inês Pereira de Gil Vicente”, Estudos de Literatura Oral, 
El testimonio que ofrece esta última canción, documentada en la tradición folclórica del siglo xx, avala la tradicionalidad y el arraigo multisecular de la voz codo como eufemismo connotador del sexo femenino, y nos permite avanzar un pequeño paso más en nuestro conocimiento, todavía limitado y parcial, de la simbología erótica en que se encierran algunas de las claves ideológicas más perdurables de nuestra lengua, literatura y cultura.

José Manuel Pedrosa Universidad de Alcalá de Henares

1 (1995), 137-143. Una versión recogida por mí de un informante del pueblo de Tobarra (Albacete), comenzaba: "Un marido le cuenta a su mujer y dice: «Oye, mujer, cada vez que paso por la puerta del cura, sale y me dice carnero mocho...»”. 